Volume 11, No.1, January - February 2022

International Journal of Advanced Trends in Computer Science and Engineering

Available Online at http://www.warse.org/IJATCSE/static/pdf/file/ijatcse021112022.pdf

https://doi.org/10.30534/ijatcse/2022/021112022

\title{
UV Room Sterilizer Automatic Motion Light Pole Based on Time Setting with Internet of Things Android Application
}

\author{
Ari Murtanto ${ }^{1}$, Budi Santoso ${ }^{2}$, Daniel Megha Purnama ${ }^{3}$, Novi Azman ${ }^{4 *}$ \\ ${ }^{1}$ Engineering and Science Faculty, Universitas Nasional, Indonesia, ari.murtanto@civitas.unas.ac.id \\ ${ }^{2}$ Engineering and Science Faculty, Universitas Nasional, Indonesia, budi.santoso@civitas.unas.ac.id \\ ${ }^{3}$ Engineering and Science Faculty, Universitas Nasional, Indonesia, danielmeghap@ gmail.co \\ ${ }^{4}$ Engineering and Science Faculty, Universitas Nasional, Indonesia, novi.azman @ civitas.unas.ac.id
}

\begin{abstract}
Sterile air is very important and has become a health standard in hospitals. In accordance with the Decree of the Minister of Health of the Republic of Indonesia No. 1204/MENKES/SK/SK/X/2004 concerning Hospital Environmental Health Requirements. UV Room Sterilizer is a tool used to reduce the number of germs in the air. However, UV C rays when exposed directly to parts of the human body can cause acute and chronic health problems on the skin, eyes, and other organs. The author makes a design for a UV sterilizer that is more safety, namely by controlling the timing and starting the tool using Android. This tool also has an hour meter that functions as a UV lamp on-lamp-state reminder. The results of the tool suitability test have a time correction value of $0.81 \% 1.12 \%$ and a relative error of $0.0049 \%$ $0.0198 \%$. In the tool that has been made the UV intensity produced on average is $90.3 \mu$ watt $/ \mathrm{cm}^{2}$ at $200 \mathrm{~cm}$, which means the tool is feasible and in accordance with BPFK standards. The UV room sterilizer that the author made in 1 hour in a $6 \times 4$-meter room can reduce the number of germs by $42.02 \%$ by $79 \mathrm{CFU} / \mathrm{m}^{3}$.
\end{abstract}

Key words: Air Quality, Healthcare, UV C, UV room sterilizer

\section{INTRODUCTION}

The Hospital Operating Room is a place to carry out elective or acute surgical procedures, which require sterile conditions. Other rooms such as the ICU room, treatment room, and poly room also require sterilization after the room is used by the patient to prevent disease transmission [1]-[4].

Ultraviolet (UV) light sterilization is one of the efforts that can be done to reduce the number of airborne germs. However, UV C rays when exposed directly to parts of the human body can cause acute and chronic health problems on the skin, eyes, and other organs [3], [5]-[7].

Utilization of the internet in the form of the internet of things has been widely used and has received more benefits for carrying out certain activities, such as in the environmental [8], [9], industrial [10]-[14], and health sectors [15]-[18]. Therefore, the use of the internet of things in the design of medical aids can help the effectiveness of its use.

\section{RESEARCH METHODOLOGY}

In this research, a hardware and software system is designed to build a UV room sterilization system. Figure 1 shows a hardware block diagram of the UV room sterilization system using the internet.

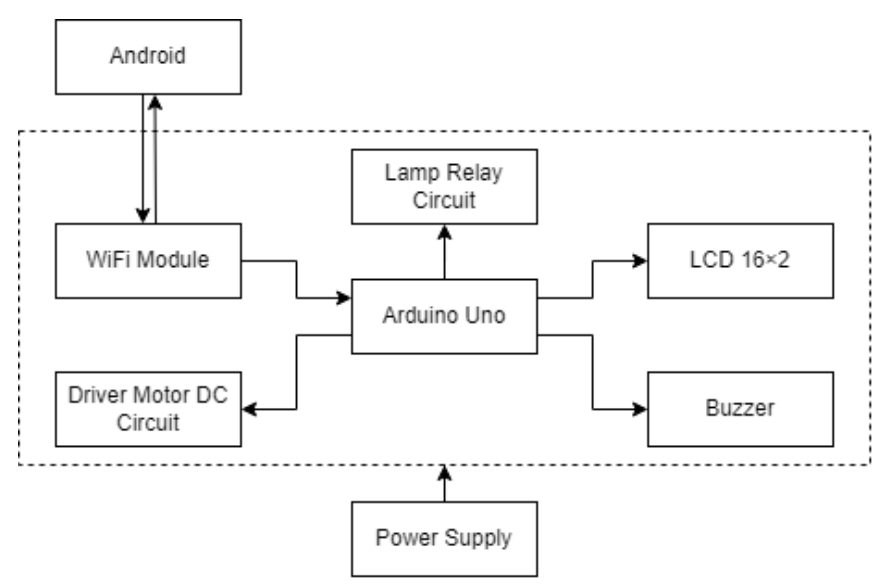

Figure 1: Hardware block diagram

Based on Figure 1, it can be explained the function of each part involved in the hardware in the UV room sterilization system

1. Power Supply

Serves as the main power source to all circuits.

2. Android

Serves to send time setting data, officer name to Arduino.

3. Wi-Fi Module

Serves to connect the cellphone to Arduino via the internet which will give commands for the tool to work.

4. Arduino Uno

Functions to receive orders from cellphones that are 
connected to the internet then process the data and give work orders to the LCD, light relay, DC motor and buzzer.

5. $16 \times 2$ LCD

Serves to display the processed results of the Arduino Uno.

6. DC motor driver circuit

Serves as a driving force for alternating DC motors.

7. Light Relay Circuit

Functions to receive orders from Arduino to turn on the lights.

8. Buzzer

Serves as an indicator of the time the use has been completed.

Then the processes that occur in the software can be seen from the program flow shown in Figure 2.

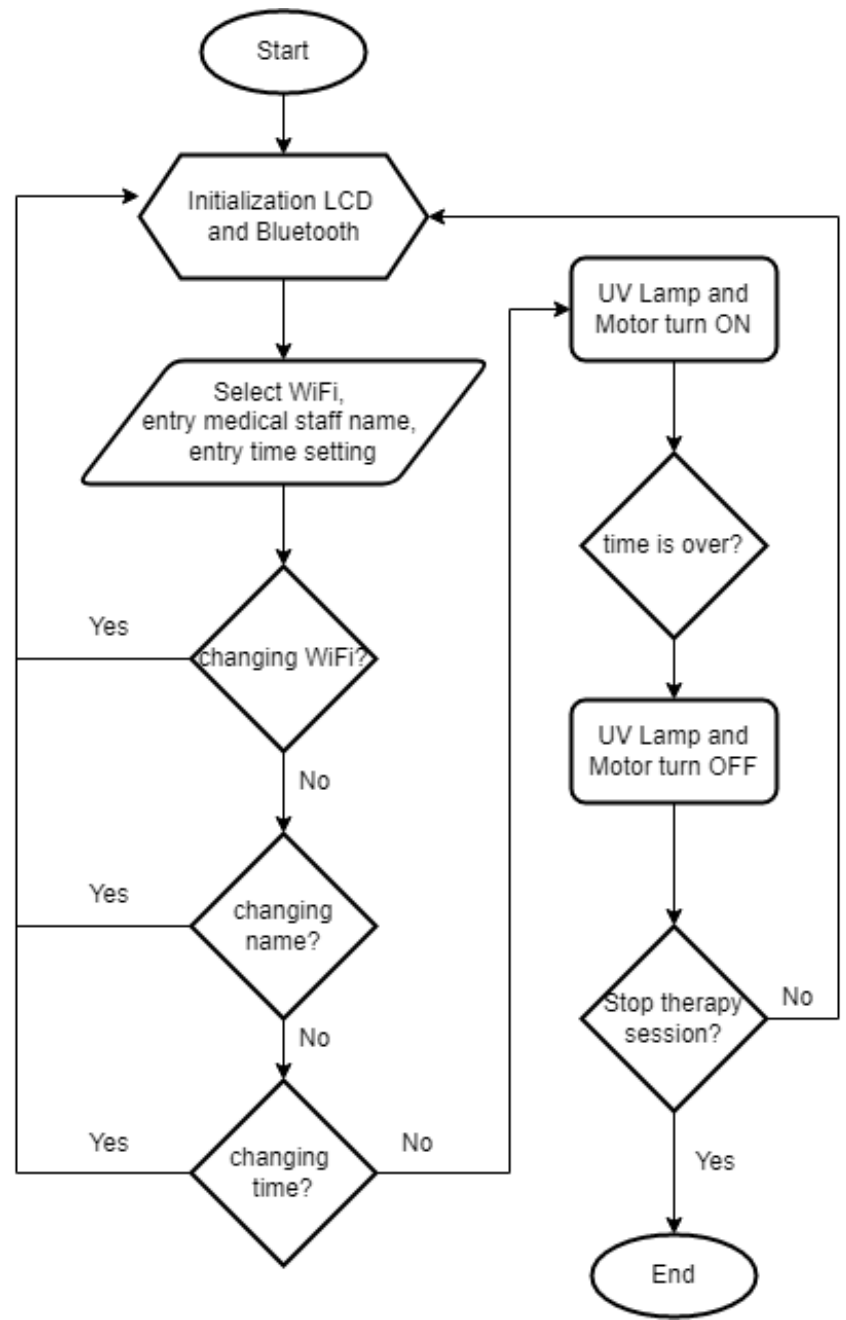

Figure 2: Software flowchart

\section{RESULTS AND DISCUSSIONS}

From the tool function test, the research data obtained from the tool measurement data. Data collection was divided into 3 (three) groups, tested for airborne germs, tested time, temperature, and intensity of UV sterilizers.

First group is testing the time of the UV sterilizer compared to a stopwatch. The data obtained from the measurements of 10 minutes, 20 minutes, 30 minutes, 40 and 50 minutes are obtained in Table 1.

Table 1: UV Sterilizer time testing

\begin{tabular}{cccccc}
\hline \multirow{2}{*}{$\begin{array}{c}\text { Stopwatch } \\
\text { time data } \\
\text { (minute) }\end{array}$} & \multicolumn{5}{c}{ UV Sterilizer time data (minute) } \\
\cline { 2 - 6 } & $\begin{array}{c}\text { 1st } \\
\text { measurement }\end{array}$ & $\begin{array}{c}\text { 2nd } \\
\text { measurement }\end{array}$ & $\begin{array}{c}\text { 3rd } \\
\text { measurement }\end{array}$ & $\begin{array}{c}\text { 4th } \\
\text { measurement }\end{array}$ & $\begin{array}{c}\text { 5th } \\
\text { measurement }\end{array}$ \\
\hline 10 & 10.11 & 10.12 & 10.11 & 10.11 & 10.11 \\
\hline 20 & 20.18 & 20.18 & 20.18 & 20.19 & 20.19 \\
\hline 30 & 30.26 & 30.27 & 30.27 & 30.27 & 30.27 \\
\hline 40 & 40.35 & 40.34 & 40.34 & 40.34 & 40.35 \\
\hline 50 & 50.4 & 50.4 & 50.41 & 50.41 & 50.4 \\
\hline
\end{tabular}

Data analysis on time test

The author takes the repetition data five times, between 10 minutes, 20 minutes, 30 minutes, 40 minutes, and 50 minutes, by comparing it with a Casio stopwatch. The data, processed to find relative errors and tool corrections for timing, can be seen in Table 2 below.

Table 2: Tool correction value and relative error for time

\begin{tabular}{ccccc} 
No & $\begin{array}{c}\text { Time on } \\
\text { stopwatch } \\
\text { (second) }\end{array}$ & $\begin{array}{c}\text { Time on } \\
\text { proposed tool } \\
\text { (second) }\end{array}$ & $\begin{array}{c}\text { Correction } \\
\text { value }(\%)\end{array}$ & $\begin{array}{c}\text { Relative } \\
\text { error }(\%)\end{array}$ \\
\hline 1 & 600 & 606.72 & 1.12 & 0.0198 \\
2 & 1200 & 1211.04 & 0.92 & 0.0119 \\
3 & 1800 & 1816.08 & 0.89 & 0.0066 \\
4 & 2400 & 2420.64 & 0.86 & 0.0059 \\
5 & 3000 & 3024.24 & 0.81 & 0.0049 \\
\hline
\end{tabular}

The relationship between the time measurement data of the UV sterilizer and the stopwatch measurement. The results of the design of the UV sterilizer have a relative error of less than $1 \%$ and the tool correction for a time of less than $2 \%$.

The second test is the Intensity test. The data obtained from the $200 \mathrm{~cm}$ distance measurement with the measurement at the center of the focal point obtained the measurement results in Table 3.

Table 3: Intensity testing on proposed UV sterilizer

\begin{tabular}{lccc}
\hline \multirow{2}{*}{$\begin{array}{l}\text { Measuremen } \\
t\end{array}$ position } & \multicolumn{2}{l}{$\begin{array}{l}\text { Intensity data on } \\
\text { UVterilizer } \\
\left(\boldsymbol{\mu W} / \mathbf{c m}^{2}\right)\end{array}$} \\
\cline { 2 - 4 } & I & \multicolumn{1}{c}{ II } & III \\
\hline $\mathrm{A}$ & 90 & 90 & 90 \\
$\mathrm{~B}$ & 91 & 90 & 90 \\
$\mathrm{C}$ & 90 & 91 & 91 \\
$\mathrm{D}$ & 90 & 90 & 91 \\
\hline
\end{tabular}


Data analysis on UV sterilizer intensity

The minimum reference standard for UV sterilizer intensity according to BPFK is more than $40 \mathrm{~W} / \mathrm{cm} 2$ with $200 \mathrm{~cm}$ at 4 points. The design of the UV sterilizer that the author designed has a good intensity.

$200 \mathrm{~cm}$ at point $\mathrm{A}$ has an average intensity of $90 \mathrm{~W} / \mathrm{cm}^{2} .200$ $\mathrm{cm}$ at point $\mathrm{B}$ has an average intensity of $90.3 \mathrm{~W} / \mathrm{cm}^{2} .200 \mathrm{~cm}$ at point $C$ has an average intensity of $90.6 \mathrm{~W} / \mathrm{cm}^{2} .200 \mathrm{~cm}$ at point $\mathrm{D}$ has an average intensity of $90.3 \mathrm{~W} / \mathrm{cm}^{2}$.

The third test is a test between the proposed tool and the germs in the room which is called the germ test.

The results of measuring the number of germs in the air in a $6 \times 4$-meter room before and after sterilization with a UV sterilizer are shown in Table 4.

Table 4: Results of measuring germs in the air

\begin{tabular}{cc}
\hline $\begin{array}{c}\text { Sterilize } \\
\mathbf{r} \text { time } \\
\text { (hour) }\end{array}$ & $\begin{array}{c}\text { Gems in } \\
\text { air } \\
\left(\mathbf{C F U} / \mathbf{m}^{\mathbf{3}}\right)\end{array}$ \\
\hline 0 & 188 \\
1 & 98 \\
2 & 30 \\
3 & 0 \\
\hline
\end{tabular}

Data analysis on air quality after using a UV sterilizer

From the measurement results in Table 4 the results of germ reduction from 0 hours to 1 hour are $90 \mathrm{CFU} / \mathrm{m}^{3}$ then 1 hour to 2 hours are $68 \mathrm{CFU} / \mathrm{m}^{3}$ which the average air germ reduction every hour is $79 \mathrm{CFU} / \mathrm{m}^{3}$. The data in Table 4 if displayed graphically is shown in Figure 3.

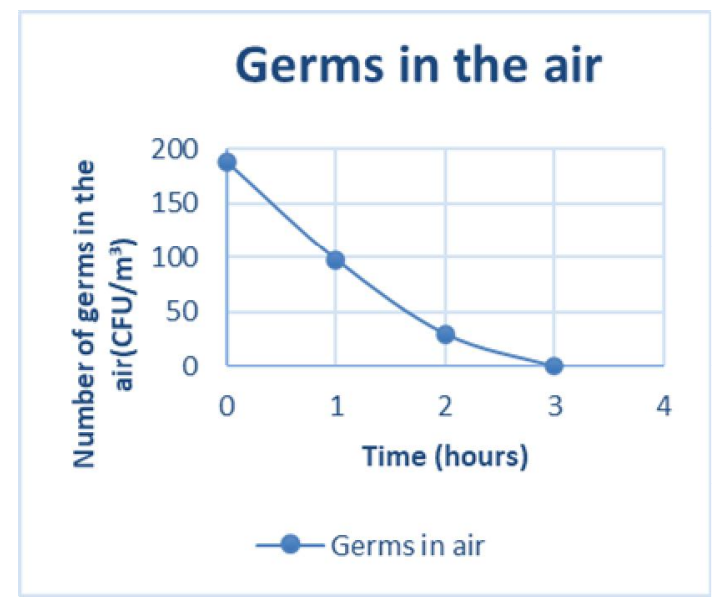

Figure 3: Germs in the air comparison the hours

\section{CONCLUSION}

From the research that has been done, it can be concluded as follows. The results of the design of the UV Room Sterilizer using Arduino which are controlled using Android with automatic movement poles can function properly. It can be seen from the operation of all sensors and the measurement results of intensity, time, which are still within the applicable standards and references. Measurement of UV room sterilizer time is the average time correction is $0.81 \% 1.12 \%$ and the error is $0.0049 \% 0.0198 \%$. The longer the time setting in the setting, the greater the time deviation. Measurement of the intensity of the UV room sterilizer according to BPFK at 200 $\mathrm{cm}$ is 40 watt $/ \mathrm{cm}^{2}$. In the tool that has been made the UV intensity produced on average is $90.3 \mu$ watt $/ \mathrm{cm}^{2}$, which means the tool is feasible to use and meets the standards. The use of the UV room sterilizer that the author made in 1 hour in a $6 \times 4-$ meter room can reduce the number of germs by $42 \%$ with the number of germs $79 \mathrm{CFU} / \mathrm{m}^{3}$.

Suggestions to continue this research is trying to variation the area of room and find the most effective the system in biggest area can covered with this proposed tools.

\section{REFERENCES}

1. M. Lindblad, E. Tano, C. Lindahl, and F. Huss. Ultraviolet-C decontamination of a hospital room: Amount of UV light needed, Burns, vol. 46, no. 4, pp. 842-849, 2020.

2. D. J. Anderson et al. Effectiveness of targeted enhanced terminal room disinfection on hospital-wide acquisition and infection with multidrug-resistant organisms and Clostridium difficile: a secondary analysis of a multicentre cluster randomised controlled trial with crossover, Lancet Infect. Dis., vol. 18, no. 8, pp. 845-853, 2018.

3. T. Ethington, S. Newsome, J. Waugh, and L. D. Lee. Cleaning the air with ultraviolet germicidal irradiation lessened contact infections in a long-term acute care hospital, Am. J. Infect. Control, vol. 46, no. 5, pp. 482-486, 2018.

4. T. de Groot, A. Chowdhary, J. F. Meis, and A. Voss. Killing of Candida auris by $\mathrm{UV} \square \mathrm{C}$ : importance of exposure time and distance, Mycoses, vol. 62, no. 5, pp. 408-412, 2019.

5. S. B. Botta, F. de Sá Teixeira, F. S. Hanashiro, W. W. R. de Araújo, A. Cassoni, and M. C. B. da Silveira Salvadori. Ultraviolet-C decontamination of a dental clinic setting: required amount of UV light, Brazilian Dent. Sci., vol. 23, no. 2, pp. 10-p, 2020.

6. B. Zhang et al. Analysis of Air Purification Methods in Operating Rooms of Chinese Hospitals, Biomed Res. Int., vol. 2020, 2020.

7. P. Chanprakon, T. Sae-Oung, T. Treebupachatsakul, P. Hannanta-Anan, and W. Piyawattanametha. An ultra-violet sterilization robot for disinfection, in 2019 5th International Conference on Engineering, Applied Sciences and Technology (ICEAST), 2019, pp. 1-4.

8. C. Gomez, S. Chessa, A. Fleury, G. Roussos, and D. Preuveneers. Internet of Things for enabling smart environments: A technology-centric perspective, J. Ambient Intell. Smart Environ., vol. 11, no. 1, pp. 23-43, 2019. 
9. M. Thibaud, H. Chi, W. Zhou, and S. Piramuthu. Internet of Things (IoT) in high-risk Environment, Health and Safety (EHS) industries: A comprehensive review, Decis. Support Syst., vol. 108, pp. 79-95, 2018.

10. W. Liang, M. Tang, J. Long, X. Peng, J. Xu, and K.-C. $\mathrm{Li}$. A secure fabric blockchain-based data transmission technique for industrial Internet-of-Things, IEEE Trans. Ind. Informatics, vol. 15, no. 6, pp. 3582-3592, 2019.

11. G. D. L. T. Parra, P. Rad, and K.-K. R. Choo. Implementation of deep packet inspection in smart grids and industrial Internet of Things: Challenges and opportunities, J. Netw. Comput. Appl., vol. 135, pp. 32-46, 2019.

12. H. Li and A. V Savkin. Wireless sensor network based navigation of micro flying robots in the industrial internet of things, IEEE Trans. Ind. informatics, vol. 14, no. 8, pp. 3524-3533, 2018.

13. M. Aazam, S. Zeadally, and K. A. Harras, Deploying fog computing in industrial internet of things and industry 4.0, IEEE Trans. Ind. Informatics, vol. 14, no. 10, pp. 4674-4682, 2018.

14. Y. Liu, K. Wang, Y. Lin, and W. Xu. LightChain: a lightweight blockchain system for industrial internet of things, IEEE Trans. Ind. Informatics, vol. 15, no. 6, pp. 3571-3581, 2019.

15. N. Azman, M. K. Bin Abd Ghani, S. R. Wicaksono, B. Kurniawan, and V. V. R. Repi. Insomnia analysis based on internet of things using electrocardiography and electromyography, Telkomnika, vol. 18, no. 3, 2020.

16. N. Azman, I. T. Anggraini, S. R. Wicaksono, and F. Djauhari. Design of temperature and humidity monitoring baby incubator based on internet of things, Int. J. Adv. Trends Comput. Sci. Eng., vol. 9, no. 5, pp. 8390-8396, 2020.

17. F. Hoet, W. Libert, C. Sanida, S. Van den Broecke, A. V Bruyneel, and M. Bruyneel. Telemonitoring in continuous positive airway pressure-treated patients improves delay to first intervention and early compliance: a randomized trial, Sleep Med., vol. 39, pp. 77-83, 2017.

18. N. Azman, M. K. A. Ghani, S. R. Wicaksono, and L. Salahuddin, The Development of IoT Tele-Insomnia Framework to Monitor Sleep Disorder, Int. J. Adv. Trends Comput. Sci. Eng., vol. 8, no. 6, pp. 2831-2839, 2019. 